Pathologe 2021 - 42 (Suppl 2):S218-S219 https://doi.org/10.1007/s00292-021-01017-5 Angenommen: 1. Oktober 2021 Online publiziert: 20. Oktober 2021 (c) Springer Medizin Verlag $\mathrm{GmbH}$, ein Teil von Springer Nature 2021

\section{Axel Georgii}

02.08.1927-07.02.2021

\author{
Hans H. Kreipe
}

Institut für Pathologie, Medizinische Hochschule Hannover, Hannover, Deutschland

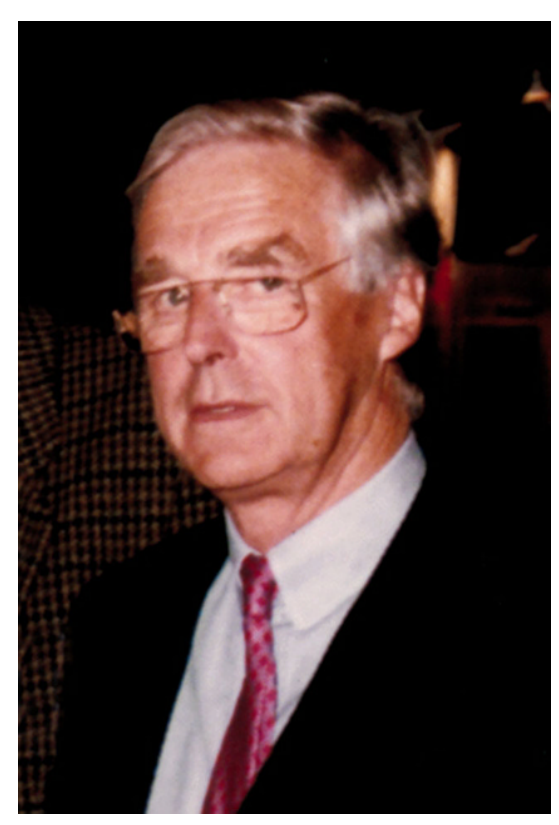

Am 7. Februar dieses Jahres ist im Alter von 93 Jahren der Gründungsdirektor und langjährige Leiter des Instituts für Pathologie der Medizinischen Hochschule Hannover (MHH), Prof. Dr. med. Axel Georgii, verstorben. Vorangegangen war ein häuslicher Sturz einige Wochen zuvor. A. Georgii wurde im Jahre 1968 auf den Lehrstuhl für Allgemeine Pathologie und Pathologische Anatomie der $\mathrm{MHH}$ berufen und leitete das neu gegründete Pathologische Institut bis zu seiner Pensionierung im Jahre 1997.

A. Georgii ist als Sohn eines Arztes in München aufgewachsen und hat in München-Pasing das dortige humanistische Gymnasium besucht. Seine Schulzeit wurde im August 1944, kurz vor Kriegsende, durch die Einberufung zur Wehrmacht unterbrochen. Nachdem er in amerikanische Kriegsgefangenschaft geraten war, konnte er 1948 nach einem weiteren Schuljahr das Abitur an der Oberrealschule München Gräfeling ablegen. Im folgenden Jahr zum Sommersemester 1949 immatrikulierte er sich für Medizin an der Ludwig-Maximilians-Universität zu München (LMU), wo er auch 1954 das Staatsexamen abgelegte. Abgesehen von zwei Auslandssemestern an der LeopoldFranzens-Universität zu Innsbruck, hat er die ersten prägenden Jahrzehnte seines Lebens in der bayerischen Hauptstadt verbracht, zu der und dem Land eine lebenslange innige Verbindung bestehen geblieben ist. Die letzten Jahre nach seiner Emeritierung haben ihn dem geliebten Land wieder nähergebracht, und er hat sie idyllisch in Schondorf am Ammersee verbracht.

Zwar hat er seine Promotionsschrift mit dem Titel „Vergleichende Darstellung der Möglichkeiten plastischer Mammaoperationen" in der Chirurgischen Poliklinik angefertigt, doch hat er bald den Weg in die klinisch-theoretische Medizin, speziell die Pathologie, gefunden. Er trat in das bis 1956 von Werner Hueck und danach von Walter Büngeler geleitete Institut für Allgemeine Pathologie und Pathologische Anatomie der LMU ein. Ein halbes Jahr verbrachte er in der II. Medizinischen Universitätsklinik. Bereits 1959 erfolgte die Habilitation über die experimentelle Erzeugung von Leukämien. Auch in der Folgezeit befasste er sich in experimentellen Arbeiten mit der Ätiologie von Leukämien. Seine experimentellen Arbeiten konnten hochrangig publiziert werden (z. B. Georgii A, Lenz I. Failure to propagate a lactic dehydrogenase-elevating agent from mice tumours in mice embryo cultures. Nature. 1964; 202:1228-9; Georgii A, Thorn L, Wrba H. Action of Riley's enzyme-elevating virus on tumour-bearing mice. Nature. 1966; 209:929-30). Ferner fand er in dieser Zeit Anschluss an die Grup- 
pe von R. Burkhard, die in der Abteilung für Knochenmarkdiagnostik an der Medizinischen Klinik Innenstadt der LMU in Kunststoff eingebettete Beckenkammtrepanate zur Diagnostik und Klassifikation von Erkrankungen des blutbildenden Systems inaugurierten. Insbesondere für die Erkennung und Klassifikation von chronischen myeloproliferativen Erkrankungen, wie die myeloproliferativen Neoplasien damals bezeichnet wurden, bedeutete die histologische Dimension eine notwendige Präzisierung. Das Münchener Klassifikationsprinzip, beruhend auf der Linienbeteiligung an der Proliferation, der megakaryozytären Atypie und der Faservermehrung bildete die Grundlage der sog. „Hannover-Klassifikation" und hat auch durch die Arbeiten des langjährigen Mitarbeiters von A. Georgii, J. Thiele, Eingang in die derzeit gültige WHO-Klassifikation myeloproliferativer Neoplasien gefunden. Die histologische Knochenmarkdiagnostik mit Einsendungen aus ganz Deutschland ist nach seinem Ruf nach Hannover, wo er ein Knochenmarkregister aufbaute, ein gewichtiger Schwerpunkt seiner histopathologischen Diagnostik geblieben.

Von München aus wurden die Geschicke der 1965 neu gegründeten $\mathrm{MHH}$, an die A. Georgii 1968 berufen wurde, wesentlich mitbestimmt. Hans Georg Borst, Sohn des Pathologen Max Borst, dem langjährigen Leiter des Pathologischen Instituts der LMU, wurde von München nach Hannover an die MHH als Leiter des Departements für Chirurgie berufen. In einer der ersten chirurgischen Kliniken in Deutschland setzte er das Konzept der Organspezialisierung und Abtrennung der Unfallchirurgie um. Sein Oberarzt Rudolph Pichlmayr, später Leiter der Viszeralchirurgie, baute mit herausragender und internationaler Sichtbarkeit die Organtransplantation an der $\mathrm{MHH}$ auf. Noch heute bildet sie einen der klinischen und wissenschaftlichen Schwerpunkte der Hochschule. A. Georgii stieß somit 1968 an der MHH auf einen aktiven und vernetzten Münchener Nidus, als er Pathologievorlesungen zum Sommersemester 1968 für die ersten 37 Studierenden der $\mathrm{MHH}$, damals im 7 . Semester, aufnahm. Als Institut wurde ihm ein Provisorium im städtischen Oststadtkrankenhaus zur Verfügung gestellt. Wie er selbst anlässlich der Eröffnung der 72. Tagung der Deutschen Gesellschaft für Pathologie 1988 in Hannover schreibt: „Zehn Jahre lang ist geplant, gebaut und verwirklicht worden ... Das hat die erste Generation der aus München mitgekommenen sechs Damen und Herren, A. Cardosa, A. Feindt, P.H. Krause, H. Ostertag, P. Ries, K.-F. Vykoupil und $\mathrm{H}$. Zobl sehr stark belastet, weil die ärztliche Versorgung der wachsenden Hochschule und die wachsenden Studentenzahlen auch betreut werden mussten". Die in der MHH und dem Institut als Kongressort aufgenommenen Besucher der 72. Jahrestagung der DGP 1988, zu denen auch ich gehörte, konnten das moderne, entsprechend seiner Planung entworfene und seit 1977 fertig gestellte Institutsgebäude in bewundernden Augenschein nehmen. Noch heute beheimatet das damals neu erstellte Gebäude die Pathologie, und die Institutsangehörigen profitieren noch heute von der weitsichtigen und großzügigen Planung.

Zum Nachbarn im Norden, dem Kieler Institut für Pathologie, an dem ich damals tätig war, bestand ein sehr gutes Verhältnis, insbesondere zu der Arbeitsgruppe von M.R. Parwaresch. Es ergaben sich über die Hämatopathologie hinausgehende, vielfältige Interaktionen. Zum Erlernen des molekularen BCR-ABL-Nachweises verbrachte sein damaliger Assistent und heutige Leiter der Freiburger Pathologie, M. Werner, einen längeren Hospitationsaufenthalt an der Förde. Im Gegenzug wurde A.M. Gassel, heute Oberhausen, im Hannoveraner Institut aufgenommen, um die histopathologische Abstoßungsdiagnostik zu erlernen. Ihre farbigen Berichte über das, was sie in Hannover gesehen hatte, sind im Gedächtnis geblieben. Auch fanden Doktoranden aus Kiel eine Anstellung am Institut in Hannover.

A. Georgii und seine Arbeitsgruppe wurden 1973 mit dem Johann Georg Zimmermann-Krebspreis, einem der höchstdotierten Preise für Krebsforschung in Deutschland, ausgezeichnet. Als Generalsekretär der Deutschen Krebsgesellschaft von 1976 bis 1984 hat er wesentliche Akzente in der nationalen Krebsforschung, auch über die Pathologie hinaus, gesetzt.

Wieviel an einer neugegründeten Hochschule der ersten aufbauenden Generation zu verdanken ist, haben die Angehörigen der zweiten Generation an der Hochschule immer vor Augen gehabt, und sie gedenken in Dankbarkeit und Anerkennung Prof. Dr. A. Georgii und dessen, was er geschaffen und weitergegeben hat.

Korrespondenzadresse

Prof. Dr. med. Hans H. Kreipe

Institut für Pathologie, Medizinische

Hochschule Hannover

Carl-Neuberg-Str. 1, 30625 Hannover,

Deutschland

kreipe.hans@mh-hannover.de 